\title{
Association between betel nut consumption and folate deficiency among pregnant women in rural Bangladesh
}

\section{Manzur Kader}

Department of Women's and Children's Health, International Maternal and Child Health (IMCH),

Uppsala University, Sweden

Address for the Correspondence: Mr. Manzur Kader, Department of Women's and Children's Health, International

Maternal and Child Health, Uppsala University, SE - 75185 Uppsala, Sweden. E-mail: manzur_physio@yahoo.

com

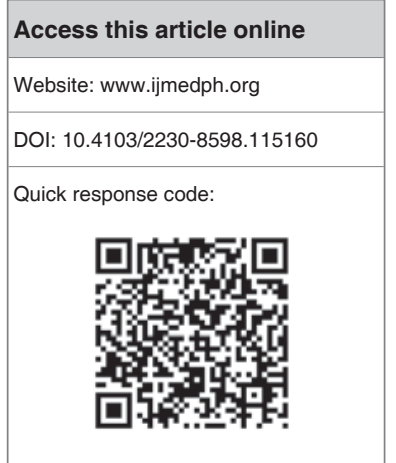

Background: Betel nut (BN) or areca nut (AN) chewing habits on its own or with other ingredients including chewing tobacco are highly prevalent in many South East Asian countries as well as among the migrants from these countries residing around the world. The major alkaloid arecoline in the $\mathrm{BN}$ has been found to carcinogenic and to be associated with a range of health risks, including negative effects on pregnancy outcomes. Pregnancy imposes stress on folate stores because of increased requirements for growth of maternal tissues, fetus, and placenta. Folate deficiency during pregnancy is a major public health concern as is associated with many adverse health outcomes including neural tube defects, low birth weight, preterm birth, and delayed maturation of the nervous system, growth retardation, and megaloblastic anemia. Objective: To investigate any association between BN consumption and folate status among pregnant women in rural Bangladesh. Materials and Methods: Data of 730 pregnant women aged $14-50$ years from the Maternal and Infant Nutrition Intervention in Matlab (MINIMat) trial in Bangladesh were included in this study. Logistic regression analysis and analyses of covariance (ANCOVA) were used. Results were adjusted for potential confounders. Results and Interpretation: Two-third (63\%) of the women consumed BN and $17 \%$ had folate deficiency. The women who consumed BN combined with chewing tobacco were 2.57 times more likely to have folate deficiency $(\mathrm{OR}=2.57 ; 95 \% \mathrm{Cl}=1.23-5.36 ; P=0.012 ;)$ and the women who consumed $\mathrm{BN} 2-3$ times/day were 2.51 times more likely to develop folate deficiency among users (OR $=2.51 ; 95 \% \mathrm{Cl}=1.07-5.92 ; P=0.035$ ). Mean serum folate levels were significantly lower among BN users as compared to nonusers. Conclusion: The results suggest that betel nut consumption combined with chewing tobacco is associated with lower serum folate level and folate deficiency among pregnant women in rural Bangladesh. Strategies are needed for prevention and control of betel nut consumption in order to prevent adverse health outcomes.

Key words: Betel nut, chewing tobacco, folate deficiency, pregnant women

\section{INTRODUCTION}

Betel nut $(\mathrm{BN})$ or areca nut (AN) is the seed of the areca palm (Areca catechu), which grows on the Indian subcontinent and in South East Asia. Betel nut is mainly consumed by chewing on its own or in combination with a range of other ingredients. Betel nut consumption is a popular social habit and a ritual. Almost $15 \%$ of the world's population (600 million people) currently has BN chewing habits. ${ }^{[1,2]}$ Betel nut use is popular in India, Bangladesh, Sri Lanka, Myanmar, Maldives, Taiwan, and few islands in the South Pacific. It is also popular in many areas of Thailand, Malaysia, Indonesia, China, Philippines, Vietnam Cambodia, Laos, and among migrant populations from these countries residing around the world. Betel nut is an important agricultural product in these countries. ${ }^{[2,3]}$

Betel nut is sold or consumed as a food substance, although its food value is uncertain. Ripe betel nut is orangish yellow in color and the consumable part is the seed (endosperm), which is separated from the fibrous pericarp. There are varieties of ways to consume the betel nut. It can be consumed by itself as fresh or dried or it is processed by boiling, baking, or roasting before consumption. The fermented betel nut is also popular in some countries, especially in Eastern India and southern Sri Lanka. In Taiwan, unripe green betel nut is often consumed and has an appearance as a small olive. ${ }^{[2,4]}$ 
The method of consumption or chewing can vary widely from country to country, but the most commonly described form is the 'quid' (synonymous with 'pan' or 'paan') or folded leaf package that is made of a betel leaf, sliced betel nut, and paste of lime (calcium hydroxide). Smokeless or chewing tobacco is another important ingredient added to BN products mainly in India and Southeast Asia. Tobacco is not usually added in Taiwan, Malaysia, Cambodia, and China. Some other common ingredients are sweeteners, various spices, such as cardamom, cloves, camphor, nutmegs, fennel etc., to suit individual taste and local custom. This quid is placed in the mouth and chewed episodically to extract the juice. ${ }^{[2,3]}$

Due to very positive advertising strategies and aggressive campaigns, some BN products have become very popular among all population groups, even among children in many south Asian counties and in migrant communities living in the United Kingdom. Pan masala, Gutkha, and Zarda are such type of products. Pan masala is basically an industrial betel nut product containing cardamom, lime, and a number of flavoring materials. Gutkha is a type of pan masala, which also contains flavored chewing tobacco. Both products are often sweetened to enhance the taste. Zarda is a type of flavored chewing tobacco, which is popular in many countries in South Asia. ${ }^{[2,4,5]}$

The consumption of $\mathrm{BN}$ has high addictive and abuse potential, as strong as cigarettes. So its habitual and chronic daily use is well recognized in many cultures with almost $50 \%$ of users consuming on a daily basis. ${ }^{[2,6]}$ Even early initiation of betel nut use with tobacco products among school children in Bangladeshi communities in the United Kingdom is now a common situation. ${ }^{[4,6]}$ The reported prevalence of betel quid chewing varies across Asian countries: India (Mumbai) - 34.5\% among men, 27.2\% among women; Thailand $16 \%$ men, $19 \%$ women; Taiwan $-28.2 \%$ men, $1.4 \%$ women; ${ }^{[4]}$ and Cambodia $-6.8 \%$ men, $40.6 \%$ women. ${ }^{[1,2]}$ The prevalence is also very high among many migrant populations living in the United Kingdom. The major migrant communities include those originating from Bangladesh, Pakistan, Sri Lanka, and India (mainly Gujarat). The prevalence of betel quid chewing has been estimated in British Bangladeshi from $78 \%$ to $96 \%$ and in British mixed Asian groups from $27 \%$ to $47 \%{ }^{[7]}$ There is an increasing trend of betel quid use among women in Bangladesh. Of all types of tobacco products used, $47 \%$ was betel quid and $25 \%$ was dried tobacco consumption among women when investigated on the national level. ${ }^{[8]}$ People with lower socioeconomic status, women, older people, smokers, less educated, and urban people are more likely to chew the $\mathrm{BN} .{ }^{[7,9]}$

Betel quid chewing has been claimed to produce a sense of well-being, sweeten the breath, dispel nausea, remove intestinal helminthes, strengthen gum, satisfy hunger, promote digestion, reduce depression, etc. Women claim that betel quid chewing in the first trimester of pregnancy can give relief from pregnancy-related nausea. ${ }^{[3,10]}$ Information is scarce, however, regarding effects of BN use on pregnancy outcomes and nutritional status.

Betel nut contains $5-40 \%$ of different polyphenols as well as many types of alkaloids such as arecoline, arecaidine, guavacoline, and guavacine. The main alkaloid is arecoline, present up to $1 \%$ of its dry weight and other alkaloids are very small in amount. ${ }^{[5,11]}$ Many carcinogenic properties of $\mathrm{BN}$ have been identified in a large number of experimental studies. ${ }^{[4-6,12,13]}$ Several carcinogens are derived from $\mathrm{BN}$ alkaloids and commonly documented carcinogens are nitrosamine products. Nitrosamines are produced by nitrosation of the alkaloid in dried stored nuts, in the mouth and especially in the acidic condition of stomach. The main three betel nut specific nitrosamines are $N$-nitrosoguvacoline (NGL), N-nitrosoguvacine (NGC), and 3-methylnitrosaminopropionitrile (MNPN) that were detected in the saliva of betel quid chewers with or without tobacco. Although betel nut specific nitrosamines have been well documented as oral carcinogens, but the favorable acidic $\mathrm{pH}$ condition of stomach can induce nitrosation of secondary and tertiary amines among consumers. It is even 2-3 times more carcinogenic with ingested tobacco in the stomach. ${ }^{[4,12,13]}$ Thus, the betel quid chewer who swallows the quid can be further exposed to these endogenous nitrosamines, which can lead to metabolic diseases of other organs via gastrointestinal absorption.

Several polyphenols in betel nut have been shown to be genotoxic probably by formation of reactive oxygen species (ROS) in the chewer's saliva. ROS causes oxidative stress or oxidative degradation where the cell is unable to counterbalance. ROS can cause many harmful effects such as oxidative and chromosomal damage of DNA, which could be involved in several stages of the carcinogenic process in oral mucosa. ${ }^{[5,14]}$

Human studies have found that arecoline affect both sympathetic and parasympathetic nervous systems. Arecoline appears to have a stimulating effect upon the sympathetic system with elevation of adrenaline and noradrenaline levels. However, it also stimulates the parasympathetic activities characterized by dilation of the pupil, increase in skin temperature, pulse rate, and systolic blood pressure. These effects on the autonomic nervous system possibly occur in a dose-dependent manner where a higher dose stimulates the parasympathetic activity. ${ }^{[6,13,15]}$ Some alkaloids have anti-muscarinic activities on smooth muscles. They can bind to GABA receptors in the brain and act as inhibitors to GABA receptors and pose extensive effects on the brain, pancreas, cardiovascular system, lungs, and gastrointestinal tract. ${ }^{[13,15]}$ Although chewing leads to gastrointestinal absorption when it is swallowed, the primary route is direct systemic absorption through buccal and sublingual mucosa that leads to an onset of effects within $5 \mathrm{~min}$ and can last for 2-3 h among consumers. In some rare cases, this can cause serious physical problems such as cholinergic crisis, asthma attack, psychosis, and cardiac arrhythmias or aggravating cardiac diseases in vulnerable patients. ${ }^{[16,17]}$

Harmful effects of $\mathrm{BN}$ have been observed in experimental studies on human embryos and pregnant women. ${ }^{[18-20]}$ There is evidence that the alkaloid arecoline in the BN can be found in the neonatal biological matrices of infants born to mothers, who were exposed to arecoline during pregnancy. In addition, its cytotoxicity and carcinogenic effects have been recognized and found in meconium, 
cord sample, and urine. ${ }^{[18]}$ Arecoline has also been found to relax human umbilical vessels in a dose-dependent manner. In addition, arecoline has been found to inhibit endothelial cell proliferation and arrest cell cycle in a dose-dependent manner. ${ }^{[19]}$ This is further supported by a study of betel nut on DNA damage by inducing sister-chromatid exchange (SCE). The betel nut induces SCE more in pregnant women than in normal women. ${ }^{[20]}$ Thus, $\mathrm{BN}$ is likely to produce adverse pregnancy outcomes among pregnant women by inducing SCE and increasing DNA susceptibility to damage.

Arecoline in BN may directly stimulate the central nervous system. This process includes a rapid crossing of the blood-brain barrier, acceleration of heart rate, increasing of blood flow in carotid arteries, but decrease in diastolic blood pressure via a peripheral cholinergic effect. ${ }^{[21]}$ Accordingly, this might reduce maternal-fetal blood flow, which may have a negative effect on birth weight.

Some studies found that use of betel nut/quid was associated with thiamine deficiency, ${ }^{[22,23]}$ aggravated effects of vitamin-D deficiency, ${ }^{[24]}$ and was associated with central obesity, hyperglycemia, diabetes mellitus, ${ }^{[13,25]}$ cirrhosis, ${ }^{[26]}$ and goiter. ${ }^{[27]}$ Various studies have shown that betel nut use during pregnancy has adverse effect on birth outcomes, including low birth weight, shorter birth length, and preterm delivery. ${ }^{[28,29]}$ A recent study from eastern and southern Taiwan among aborigines found the prevalence of betel quid consumption during gestation to be $36.7 \%$. Two-third of aboriginal women chewed betel quid and a majority ( $86 \%$ ) continued their habit during pregnancy. ${ }^{[28]}$ Only $45 \%$ of the participants were aware of harmful effects of betel quid. ${ }^{[29]}$ In Mumbai, India, 17.1\% of pregnant women reported to have used betel quid with tobacco regularly during pregnancy. ${ }^{[30]}$

Folate or folic acid is a water-soluble vitamin of the B-complex group and plays an important role for optimal health, growth, and development. Folate is found naturally in food and folic acid is the synthetic form of folate. Folate acts as cofactor or co-enzyme and is involved in a variety of physiological processes such as amino-acid metabolism, maintenance and repair of genome, regulation of gene expression, neurotransmitter synthesis, and the formation of myelin. ${ }^{[31]}$

Pregnancy imposes stress on folate stores because of increased requirements for growth of maternal tissues, fetus, and placenta. There is demand for folate for uterine enlargement and for rise in blood volume, which requires increased red cell production. Increased folate requirements during infancy, lactation, concurrent infection, and malignancy may lead to folate deficiency. Folate deficiency during pregnancy is a major public health concern as is associated with many adverse outcomes including increased risk for neural tube defects, low birth weight, preterm birth, delayed maturation of the nervous system, growth retardation, and megaloblastic anemia. ${ }^{[31,32]}$ A high prevalence of folate deficiency among Bangladeshi men and women has been documented in many studies and the prevalence of deficiency varies from $13 \%$ to $25 \%$ among adolescent girls and women in Bangladesh. ${ }^{[33-35]}$
The objective of this study was to investigate any association between $\mathrm{BN}$ use or any form of betel quid use and folate status among pregnant women in rural Bangladesh.

\section{MATERIALS AND METHODS}

\section{Study area}

The data were received from a randomized control trial in Matlab, Bangladesh. Matlab is subdivision in Bangladesh, about $55 \mathrm{~km}$ southeast of Dhaka, the capital of Bangladesh. Matlab is a major rural field site and a reputed public health resource for the world. This site represents a model for public health strategies around the world. Matlab has been under health and demographic surveillance system (HDSS) of the International Centre for Diarrheal Disease Research, Bangladesh (ICDDR, B) since 1966 and this HDSS covers about 225,000 population living in Matlab area and provides necessary socio demographic data to plan, conduct, and evaluate various types of public-health interventions. ${ }^{[36]}$

\section{Study population and study design}

The subjects were participants in the Maternal and Infant Nutritional Interventions in Matlab (MINIMat) trial, Bangladesh. MINIMat is a large food and multiple micronutrient supplementation trial in pregnant women, including long-term follow-up of their children, and of the mothers into the next pregnancy. The original study population consisted of 4436 women who were invited and randomized for different interventions. Pregnant women (aged between 14-50 years) who lived in the study area (Matlab) were invited to this trial once their pregnancy was confirmed with a urine test and an ultrasound showing gestational age less than 14 weeks. Random subsets of 730 women representative of the full year 2002 were selected for folate status assessment. So a total of 730 women with available serum folate measurements were included in the analysis of this research work.

\section{Variables}

The outcome variable is folate deficiency among women at week 14 of gestation. Women with serum folate levels less than $6.8 \mathrm{nmol} / \mathrm{L}$ were defined as folate deficient. Serum folate levels were also available as a continuous variable. Serum vitamin B-12 less than $150 \mathrm{pmol} / \mathrm{L}$ was defined as vitamin B-12 deficiency.

In the original MINIMat study, women were asked about their consumption of betel nut during their last pregnancy at the time of their postpartum visit. If they had consumed BN, they were further asked if betel nut was consumed as dry or fresh or with combination of other ingredients such as betel leaf, lime, and zarda (chewing tobacco). The types of betel nut consumption was recoded into these alternatives: Nonuser of betel nut $(\mathrm{BN})$ or user of $\mathrm{BN}$; nonuser of $\mathrm{BN}, \mathrm{BN}$ (fresh or dry) with chewing tobacco and $\mathrm{BN}$ (fresh or dry) without chewing tobacco; nonuser of $\mathrm{BN}$, dry $\mathrm{BN}$ with chewing tobacco and fresh $\mathrm{BN}$ with chewing tobacco; dry $\mathrm{BN}$ without chewing tobacco and fresh $\mathrm{BN}$ without chewing tobacco. 
Frequency of BN was grouped as no consumption, less than daily, once a day, two or three times a day. Women's age was recoded into three age groups (14-24, 25-30, and $>30)$. Parity was recoded into no child, one child, two children, or more than two children. Body mass index (BMI) was computed, then categorized according to WHO definition of underweight (BMI <18.5), normal weight (BMI 18.5-24.9), overweight (BMI 25-29.9), and obese (BMI of 30 or greater).

The socioeconomic status of the women was assessed by using a household asset score recoded into quintiles expressing the wealth index as poor, lower middle, middle, upper middle, and rich. Women's literacy was classified as ability to read and write or illiterate.

\section{Statistical Analysis}

Merging, cleaning of data and control of missing values were performed as the primary step of data analysis. Serum folate measurement at week 14 was taken as outcome variable. Serum folate measurements were available for 730 women; thus, all analyses refer to these women.

Baseline descriptive characteristics are presented as number, percentage, means, and standard deviations (SDs). Associations between exposure (BN use) or potential confounding variables and dichotomous outcomes of folate deficiency were analyzed by use of Pearson's Chi-square test.

Multivariate analyses were used to evaluate the independent association of the identified factors of importance for folate deficiency. Firstly, unadjusted odds ratio (OR) was obtained from binary logistic regression models between outcome variable of folate deficiency and each independent variable for types of betel quid consumption or various frequency of betel quid consumption. Thereafter, potential confounders were added to the models one by one and were retained in the final model if they changed a significant beta coefficient of the variables of key interest with $>10 \%$. Identified potential confounders were calculated asset score, women's age, serum vitamin B-12 status and women's literacy.

Analyses of covariance (ANCOVA) models were performed to analyze whether folate levels were associated with betel quid consumption. Other covariates, that is, asset score, age, serum vitamin B-12 status and literacy that could influence the dependent variable were added to the model to get adjusted models with mean, $P$ value and $95 \%$ confidence interval.

All statistical analyses were performed by using IBM SPSS Statistics 19 for Window (SPSS Inc, Chicago, IL). Results with $P<0.05$ were considered to be statistically significant.

\section{RESULTS}

\section{Basic characteristics}

The basic characteristics of the women are presented in Table 1. On average the women were 26 years old, $45 \mathrm{~kg}$ in weight, and $150 \mathrm{~cm}$ in

\begin{tabular}{|c|c|c|}
\hline Variables & $N$ & Mean \pm SD \\
\hline Age & 730 & $26.6 \pm 5.9$ \\
\hline Weight & 726 & $45.3 \pm 6.9$ \\
\hline Height & 730 & $149.9 \pm 5.4$ \\
\hline BMI & 726 & $20.1 \pm 2.7$ \\
\hline \multirow[t]{2}{*}{ Parity } & 730 & $1.4 \pm 1.4$ \\
\hline & $N$ & $\%$ \\
\hline \multicolumn{3}{|l|}{ Asset score } \\
\hline Poor & 130 & 17.8 \\
\hline Below middle & 172 & 23.6 \\
\hline Middle & 150 & 20.5 \\
\hline Upper middle & 130 & 17.8 \\
\hline Rich & 148 & 20.3 \\
\hline \multicolumn{3}{|l|}{ Literacy } \\
\hline Illiterate & 245 & 33.6 \\
\hline Can read and write & 485 & 66.4 \\
\hline \multicolumn{3}{|l|}{ Betel nut consumption } \\
\hline Non user of BN & 238 & 38.8 \\
\hline Betel nut user & 376 & 61.2 \\
\hline BN without chewing tobacco & 317 & 51.6 \\
\hline BN with chewing tobacco & 60 & 9.8 \\
\hline Dry betel nut & 299 & 57.7 \\
\hline Fresh betel nut & 18 & 3.6 \\
\hline \multicolumn{3}{|l|}{ Folate status } \\
\hline Nondeficient & 606 & 83 \\
\hline Deficient & 124 & 17 \\
\hline
\end{tabular}

height. The mean BMI was $20 \mathrm{~kg} / \mathrm{m}^{2}$ and mean parity was 1.4. Around two-third (63\%) of women could read and write in the study area.

\section{Betel nut consumption}

Almost two-third (61\%) of women consumed the BN. A majority of women (58\%) consumed dry BN and only 3.6\% consumed fresh BN. Half $(52 \%)$ of the women consumed $\mathrm{BN}$ with ingredients betel leaf and lime but without chewing tobacco and $9.8 \%$ of women added chewing tobacco with it. Regarding frequency of consumption, $10.7 \%$ women consumed BN 2-3 times per day, 13.4\% consumed once per day, and $5.6 \%$ consumed less than daily.

\section{Folate deficiency}

Of the 730 women included in this analysis, 124 (17\%) had folate deficiency Table 2.

Table 3 shows that the women who consumed betel nut with zarda (chewing tobacco) were 2.57 times more likely to have folate deficiency $(\mathrm{OR}=2.57 ; 95 \% \mathrm{CI}=1.23-5.36 ; P=0.012)$. Age factor and vitamin B-12 deficiency were also significantly associated with folate deficiency in this model. If focusing the frequency of $\mathrm{BN}$ consumption it was found that $\mathrm{BN}$ use two to three times per day (disregarding whether combined with tobacco or not) was significantly associated with folate deficiency among users $(\mathrm{OR}=2.51 ; 95 \% \mathrm{CI}=1.07-5.92 ; P=0.035)$. Asset score and literacy were not associated with folate deficiency. 


\begin{tabular}{|c|c|c|c|c|}
\hline Variables & All $N(\%)$ & Folate deficient $N(\%)$ & Nondeficient $N(\%)$ & $P$ value \\
\hline \multicolumn{5}{|l|}{ Asset } \\
\hline Poor & $130(17.8)$ & $100(13.7)$ & $30(4.1)$ & \\
\hline \multicolumn{5}{|l|}{ Score } \\
\hline Below middle & $172(23.6)$ & $141(19.3)$ & $31(4.2)$ & \\
\hline Middle & $150(20.5)$ & $127(17.4)$ & $23(3.2)$ & \\
\hline Upper middle & $130(17.8)$ & $113(15.5)$ & $17(2.3)$ & \\
\hline Rich & $148(20.3)$ & $125(17.1)$ & $23(3.2)$ & \\
\hline Total & $730(100)$ & $606(83.0)$ & $12(17.0)$ & 0.242 \\
\hline \multicolumn{5}{|l|}{ Age (year) } \\
\hline $14-24$ & 277 (39.9) & $226(32.5)$ & $51(7.3)$ & \\
\hline $25-30$ & $207(29.8)$ & $165(23.7)$ & $42(6.0)$ & \\
\hline$>30$ & $211(30.4)$ & $186(26.8)$ & $25(3.6)$ & \\
\hline Total & $695(100)$ & $577(83.0)$ & $118(17.0)$ & 0.051 \\
\hline \multicolumn{5}{|l|}{ Parity } \\
\hline No child & $241(33.0)$ & $200(27.4)$ & $41(5.6)$ & \\
\hline 1 parity & $196(26.8)$ & $156(21.4)$ & $40(5.5)$ & \\
\hline 2 parity & $152(20.8)$ & $131(17.9)$ & $21(2.9)$ & \\
\hline$\geq 3$ parity & $141(19.3)$ & $119(16.3)$ & $22(3.0)$ & \\
\hline Total & $730(100)$ & $606(83.0)$ & $124(17.0)$ & 0.407 \\
\hline \multicolumn{5}{|l|}{ BMI $\left(\mathrm{kg} / \mathrm{m}^{2}\right)$} \\
\hline Underweight & $194(26.9)$ & $163(22.6)$ & $31(4.3)$ & \\
\hline Normal weight & $487(67.6)$ & $400(55.6)$ & $87(12.1)$ & \\
\hline Overweight & $39(5.4)$ & $33(4.5)$ & $6(0.8)$ & \\
\hline Total & $720(100)$ & $596(82.8)$ & $124(17.2)$ & 0.801 \\
\hline \multicolumn{5}{|l|}{ Literacy } \\
\hline Illiterate & $245(33.6)$ & $196(26.8)$ & $49(6.7)$ & \\
\hline Can read and write & $485(66.4)$ & $410(56.2)$ & $75(10.3)$ & \\
\hline Total & $730(100)$ & $606(83)$ & $124(17)$ & 0.084 \\
\hline \multicolumn{5}{|l|}{ Vitamin B-12 status } \\
\hline Normal & 378 (53.9) & $335(47.8)$ & $43(6.1)$ & \\
\hline Deficient & $323(46.1)$ & $250(35.7)$ & $73(10.4)$ & \\
\hline Total & $701(100)$ & $585(83.5)$ & $116(16.5)$ & 0.001 \\
\hline
\end{tabular}

\begin{tabular}{|c|c|c|c|c|c|c|c|}
\hline \multirow[t]{2}{*}{ Predictors } & \multirow[t]{2}{*}{$N$} & \multirow[t]{2}{*}{ OR } & \multirow[t]{2}{*}{$\mathrm{Cl}(95 \%)$} & \multicolumn{2}{|c|}{$\begin{array}{l}\text { Adjusted OR } \\
\text { Model a }\end{array}$} & \multicolumn{2}{|c|}{$\begin{array}{l}\text { Adjusted OR } \\
\text { Model b }\end{array}$} \\
\hline & & & & OR & $\mathrm{Cl}(95 \%)$ & OR & $\mathrm{Cl}(95 \%)$ \\
\hline \multicolumn{8}{|l|}{ BN consumption } \\
\hline No consumption & 237 & Reference & & & & & \\
\hline Betel nut only & 317 & 0.97 & $0.61-1.56$ & 0.90 & $0.53-1.52$ & & \\
\hline BN with chewing tobacco & 60 & $2.39^{\star *}$ & $1.24-4.61$ & $2.57^{*}$ & $1.23-5.36$ & & \\
\hline \multicolumn{8}{|l|}{ Frequency of consumption } \\
\hline No consumption & 262 & Reference & & & & & \\
\hline Less than daily & 21 & 0.87 & $0.24-3.00$ & & & 0.62 & $0.13-2.86$ \\
\hline Once daily & 50 & 0.85 & $0.36-2.02$ & & & 1.07 & $0.40-2.87$ \\
\hline 2-3 times a day & 40 & $2.25^{*}$ & $1.06-4.76$ & & & $2.51^{*}$ & $1.07-5.93$ \\
\hline \multicolumn{8}{|l|}{ Women's age } \\
\hline 14-24 years old & 277 & $1.68^{*}$ & $1.00-2.81$ & $2.27^{*}$ & $1.17-4.40$ & 2.34 & $1.00-5.48$ \\
\hline $25-30$ years old & 107 & $1.89^{*}$ & $1.11-3.24$ & $2.56^{\star *}$ & $1.32-4.97$ & $2.70^{*}$ & $1.16-6.27$ \\
\hline$>30$ years old & 211 & Reference & & & & & \\
\hline \multicolumn{8}{|l|}{ Vitamin B-12 status } \\
\hline Normal Vitamin B-12 & 378 & Reference & & & & & \\
\hline Vitamin B-12 deficiency & 323 & $2.28^{\star}$ & $1.51-3.43$ & $2.45^{\star \star}$ & $1.51-3.98$ & $2.12^{*}$ & $1.14-3.91$ \\
\hline
\end{tabular}


The mean differences in folate levels among various types and frequency of BN consumers are shown in Table 4. The mean plasma folate levels were significantly lower for all of the $\mathrm{BN}$ users as compared to nonusers (mean 11.52, and $13.08 \mathrm{nmol} / \mathrm{L}$, respectively, $P=0.006$ ).

The mean plasma folate levels were lower for all of the betel nut users with and without chewing tobacco in comparison with nonusers (mean 10.53, 11.70, and $13.10 \mathrm{nmol} / \mathrm{L}$, respectively, $P=0.009$ and $P=0.017)$. The mean plasma folate levels were significantly lower for all of the dry $\mathrm{BN}$ users with tobacco as compared to all of the fresh $\mathrm{BN}$ users with tobacco and nonusers (mean 11.49, 11.94, and $13.08 \mathrm{nmol} / \mathrm{L}$, respectively, $P=0.006)$.

The mean plasma folate levels were significantly lower for all of the dry BN users without tobacco compare to all of the fresh $\mathrm{BN}$ user without tobacco and nonusers (mean 11.63, 12.49, and $13.08 \mathrm{nmol} / \mathrm{L}$, respectively, $P=0.016$ ). These results were significant after adjusting for potential confounding factors, that is, asset score, vitamin-12-deficiency, and literacy.

\section{DISCUSSION}

The results of this study suggest that $\mathrm{BN}$ consumption with chewing tobacco is associated with lower serum folate level and folate deficiency in pregnant women in Bangladesh.

According to ANCOVA, the BN without chewing tobacco was associated with lower folate status and in logistic regression; BN with chewing tobacco was associated with folate deficiency.

To our knowledge, this is the first study which shows that the BN consumption with chewing tobacco is significantly associated with folate deficiency amongst its consumers. Two previous studies by Gamble et al., ${ }^{[37]}$ and Pilsner et al., ${ }^{[38]}$ documented that BN use was associated with lower plasma folate levels.

The results also suggest that in addition to betel nut and chewing tobacco, vitamin B-12 deficiency is an important determinant of folate deficiency and women in fertile age (14-30 years) are vulnerable to folate deficiency. It is very well documented that vitamin B-12 deficiency is a major cause of folate deficiency. ${ }^{[32,39]}$ Folate deficiency among fertile women was relatively common in this study, which was consistent with previous studies where women below 40 years of age in Bangladesh ${ }^{[33]}$ and women between 18 and 22 years of age in India ${ }^{[40]}$ were folate deficient, $17 \%$ and $26.3 \%$, respectively.

In this study, 9.8\% of women added chewing tobacco in the betel quid, but women in Bangladeshi community living in United Kingdom reported to add more chewing tobacco, ranges from Tower Hamlets $43 \%,{ }^{[41]}$ Yorkshire $69 \%$ to Birmingham $81 \%$ in their quids. ${ }^{[4]}$ Thus, these British women with Bangladeshi background may also be more exposed to this risk factor.

Although the UK Bangladeshi women cannot be compared with rural poor women in Bangladesh, the dose-response relationship suggested in this study indicates that even betel nut use in Europe may be associated with folate deficiency problems.

Almost $17 \%$ of these women had folate deficiency. The high prevalence of folate deficiency in early pregnancy is a major concern, as it could lead to adverse pregnancy outcomes and increased health risks for both mother and child. The original study has the advantages of randomized enrolment of pregnant women over a full year of 2000 that made the results representative of the study population and hence the findings can be generalized to pregnant women in the area and most likely in common segments of Bangladesh. In the census of Matlab HDSS study area in 2005, the socioeconomic characteristics of this area were similar to that of national level. ${ }^{[36]}$

It is notable that two important potential confounders alcohol and cigarette smoking were absent among the women in this study.

This study was a cross-sectional study to investigate the association between betel nut exposure and folate status. Such a design does not give any indication of the sequence of events. This precludes possibilities to draw causal inferences from the results.

\begin{tabular}{|c|c|c|c|c|c|}
\hline \multirow{2}{*}{$\begin{array}{l}\text { Predictors } \\
\text { Betel nut consumption }\end{array}$} & \multirow[t]{2}{*}{$N$} & \multicolumn{2}{|c|}{ Unadjusted } & \multicolumn{2}{|c|}{ Adjusted $^{a}$} \\
\hline & & Mean folate (nmol/L) & Mean difference & Mean folate (nmol/L) & Mean difference \\
\hline Betel nut users & 376 & $11.41^{* *}$ & -1.51 & $11.52^{\star *}$ & -1.56 \\
\hline Non user & 238 & 12.92 & Ref. & 13.08 & Ref. \\
\hline BN with tobacco & 60 & $10.62^{*}$ & & $10.53^{* *}$ & \\
\hline BN without tobacco & 317 & $11.55^{*}$ & -0.93 & $11.70^{*}$ & -1.17 \\
\hline No use & 237 & 12.95 & Ref. & 13.10 & Ref. \\
\hline Dry BN with tobacco & 354 & $11.40^{* *}$ & & $11.49^{* *}$ & \\
\hline Fresh BN with tobacco & 22 & 11.61 & -0.21 & 11.94 & -0.45 \\
\hline No use & 238 & 12.92 & Ref. & 13.08 & Ref. \\
\hline Dry BN without tobacco & 299 & $11.50^{*}$ & & $11.64^{*}$ & \\
\hline Fresh BN without tobacco & 18 & 12.30 & -0.80 & 12.49 & -0.85 \\
\hline No use & 237 & 12.95 & Ref. & 13.08 & Ref. \\
\hline
\end{tabular}

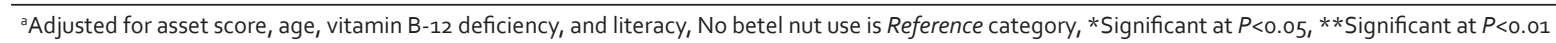


It was not possible to distinguish the association between other ingredients such as lime and betel leaf (pan) used with betel nut and the outcome. There was no previous evidence of any association of these ingredients with nutritional deficiency. Betel leaf or pan contains large amount of antioxidant carotenes $(80.5 \mathrm{mg} / \mathrm{g})$, which are known to reduce the risk of cancer. Betel leaf extracts act as effective scavengers of ROS. Betel leaves also contain several compounds such as chlorophyll, chavicol, and hydroxychavicol, which are thought to be have chemoprotective properties. ${ }^{[4,5,13]}$

Another limitation of the study was the unavailability of data on dietary intake of folic acid and vitamin B-12. A recent food base study reported that vegetables, fish, pulses, and rice are the key daily dietary items of the population in this study area. Some of the vegetables include amaranth (Amaranthus viridis), spinach (Basella alba), bitter gourd (Momordica charantia), arum (Colocasia esculenta) stem, green banana (Musa spp.), and eggplant (Solanum melongena). ${ }^{[42]}$ A majority of these food items are rich in folate; thus, the evidence suggests that the dietary folate intake is not inadequate among the women in this study setting. But eating a mainly vegetarian diet can be a cause of vitamin B-12 deficiency among the women.

Earlier published data are insufficient to provide a clear picture of the prevalence pattern of $\mathrm{BN}$ or quid chewing by Bangladeshi populations. Some of the reports reflect the habits of Bangladeshi migrant populations living in the United Kingdom. It is clear that the habit of betel quid chewing with and without tobacco is widespread among Bangladeshi population and therefore an indication of a similar pattern of the chewing habits in their home country.

\section{CONCLUSION}

The results of this study suggest that $\mathrm{BN}$ use is significantly associated with lower folate status among pregnant women and addition of chewing tobacco is associated with folate deficiency.

Although this study focused on pregnant women, lower folate status or folate deficiency is also likely in the general population who are consumers of the BN. A majority of the population in South East Asian countries may be unaware of harmful effects of betel nut and continue to consume betel nut during pregnancy. Today, betel chewing products with or without tobacco are very popular among all age groups in many South East Asian countries as well as amongst the migrant populations from these countries. And these products are shown as a safer alternative to tobacco products by aggressive marketing campaigns, which also target children and adolescents. It is important to educate individuals about the harmful effects of $\mathrm{BN}$. If the population is not educated, the consumption of $\mathrm{BN}$ may continue to future generations as part of cultural traditions. For an example, there was no difference found between the chewing habits of first- and second-generation Bangladeshi migrations in the United Kingdom. ${ }^{[1,7]}$

Strategies to prevent and control $\mathrm{BN}$ consumption are needed in order to prevent adverse health outcomes. An effective health promotion policy aimed at reducing the use of betel quid may reduce its use. There is need for more precise data on various ingredients of $\mathrm{BN}$ to distinguish their individual effects on folate deficiency.

\section{ACKNOWLEDGMENT}

I would like to express my deepest gratitude to Professor Lars Åke Persson and Senior lecturer Eva-Charlotte Ekström at Uppsala University, Sweden. It would not be possible to conduct this study without their invaluable guidance and encouragement from the beginning of my work. My special thanks to my friends Suman Kanti Chowdhury and Nirmala Perera for their comments and suggestions.

\section{REFERENCES}

1. Williams S, Malik A, Chowdhury S, Chauhan S. Socio-cultural aspects of areca nut use. Addict Biol 2002;7:147-54.

2. Gupta PC, Warnakulasuriya S. Global epidemiology of areca nut usage Addict Biol 2002;7:77-83.

3. Strickland SS. Anthropological perspectives on use of the areca nut Addict Biol 2002;7:85-97.

4. Betel-quid and Areca-nut Chewing-IARC Monographs- Vol. 85. Available from: http://monographs.iarc.fr/ENG/Monographs/vol85/mono85-6.pdf [Last accessed on 2012 Dec 20].

5. Nair U, Bartsch H, Nair J. Alert for an epidemic of oral cancer due to use of the betel quid substitutes gutkha and pan masala: A review of agents and causative Mechanisms. Mutagenesis 2004;19:251-62.

6. Winstock A. Areca nut-abuse liability, dependence and public health Addict Biol 2002;7:133-8.

7. Warnakulasuriya S. Areca nut use following migration and its consequences. Addict Biol 2002;7:127-32.

8. Craving for Nicotine: A study on Tobacco Prevalence in Bangladesh, Dhaka. Bangladesh, Dhaka: Bangladesh Institute of Development studies; Dec 2001. Available from http://www.searo.who.int/LinkFiles/ Regional_Tobacco_Surveillance_System_SentinelBangladesh.pdf [Last accessed on 2012 Dec 21].

9. Croucher R, Islam S. Socio-economic aspects of areca nut use. Addict Biol 2002;7:139-46.

10. Núñez-de la Mora A, Jesmin F, Bentley GR. Betel Nut Use among First and Second Generation Bangladeshi Women in London, UK. J Immigrant Minority Health 2007;9:299-306.

11. Lord GA, Lim CK, Warnakulasuriya S, Peters TJ. Chemical and analytical aspects of areca nut. Addict Biol 2002;7:99-102.

12. Jeng JH, Chang MC, Hahn LJ. Role of areca nut in betel quid-associated chemical carcinogenesis: Current awareness and future perspectives. Oral Oncol 2001;37:477-92.

13. Boucher BJ, Mannan N. Metabolic effects of the consumption of Areca catechu. Addict Biol 2002;7:103-10.

14. Nair UJ, Obe G, Friesen M, Goldberg MT, Bartsch H. Role of Lime in the Generation of Reactive Oxygen Species from Betel-Quid Ingredients. Environ Health Perspect 1992;98:203-5.

15. Chu NS. Neurological aspects of areca and betel chewing. Addict Biol 2002;7:111.

16. Nelson BS, Heischober B. Betel nut: A common drug used by naturalized citizens from India, Far East Asia, and the South Pacific Islands. Ann Emerg Med 1999;34:238-43.

17. Deng JF, Ger J, Tsai WJ, Kao WF, Yang CC. Acute toxicities of betel nut: Rare but probably overlooked events. J Toxicol-Clin Toxicol 2001;39:355-60.

18. Pichini S, Pellegrini M, Pacifici R, Marchei E, Murillo J, Puig C, et al. Quantification of arecoline (Areca nut alkaloid) in neonatal biological matrices by high-performance liquid chromatography/electrospray quadrupole mass spectrometry. Rapid Commun Mass spectromy 2003;17:1958-64

19. Kuo FC, Wu DC, Yuan SS, Hsiao KM, Wang YY, Yang YC, et al. Effects of arecoline in relaxing human umbilical vessels and inhibiting endothelial cell growth. J Perinat Med 2005;33:399-405. 
20. Ghosh PK, Ghosh R. Effect of Betel chewing on the frequency of sister chromatid exchange in pregnant women and women using oral contraceptives. Cancer Genet Cytogenet 1988;32:211-5.

21. Lin SK, Chang YJ, Ryu SJ, Chu NS. Cerebral hemodynamic responses to betel chewing: A Doppler study. Clin Neuropharmacol 2002;25:244-50.

22. Vimokesant SL, Hilker DM, Nakornchai S, Rungruangsak K, Dhanamitta S. Effects of betel nut and fermented fish on the thiamin status of northeastern Thais. Am J Clin Nutr 1975;28:1458-63.

23. Vimokesant S, Kunjara S, Rungruangsak K, Nakornchai S, Panijpan B. Beriberi caused by antithiamin factors in food and its prevention. Annals of the New York Academy of Sci 1982;378:123-36.

24. Ogunkolade WB, Boucher BJ, Bustin SA, Burrin JM, Noonan K, Mannan $\mathrm{N}$, et al. Vitamin $\mathrm{D}$ metabolism in peripheral blood mononuclear cells is influenced by chewing "betel nut" (Areca catechu) and vitamin D status. J Clin Endocrinol Metab 2006;91:2612-7.

25. Mannan N, Boucher BJ, Evans SJ. Increased waist size and weight in relation to consumption of Areca catechu (betel-nut); A risk factor for increased glycaemia in Asian in East London. Br J Nutr 2000;83:267-75.

26. Tsai JF, Jeng JE, Chuang LY, Ho MS, Ko YC, Lin ZY, et al. Habitual betel quid chewing as a risk factor for cirrhosis-A case-control study. Medicine (Baltimore) 2003;82:365-72.

27. Van der Bijl P, Thompson IO. Effect of aqueous areca nut extract on the permeability of mucosa. S Afr J Sci 1998;94:241-3.

28. Yang MS, Lee CH, Chang SJ, Chung TC, Tsai EM, Ko AM, et al. The effect of maternal betel quid exposure during pregnancy on adverse birth outcomes among aborigines in Taiwan. Drug Alcohol Depend 2008;95:134-9.

29. Yang MJ, Chung TC, Yang MJ, Hsu TY, Ko YC. Betel quid chewing and risk of adverse birth outcomes among aborigines in Eastern Taiwan. J Toxicol Environ Health A 2001;64:465-72.

30. Gupta PC, Subramoney S. Smokeless tobacco use and risk of stillbirth: A cohort study in Mumbai, India. Epidemiology 2006;17:47-51.

31. Djukic A. Folate-responsive neurologic diseases. Pediatr Neurol 2007;37:387-97.

32. Folic acid deficiency. Available from: http://emedicine.medscape.com/ article/200184-overview [Last accessed on 2012 Dec 20].

33. Khambalia A, O'Connor DL, Zlotkin S. Periconceptional Iron and Folate Status Is Inadequate among Married, Nulliparous Women in Rural Bangladesh. J Nutr 2009;139:1179-84.
34. Lindström $E$, Hossain MB, Lönnerdal B, Raqib R, El Arifeen $S$ Ekström EC. et al. Prevalence of anemia and micronutrient deficiencies in early pregnancy in rural Bangladesh, the MINIMat trial. Acta Obstet Gynecol Scand 2011;90:47-56.

35. Ahmed F, Khan MR, Banu CP, Qazi MR, Akhtaruzzaman M. The coexistence of other micronutrient deficiencies in anaemic adolescent schoolgirls in rural Bangladesh. Eur J Clin Nutr 2008;62:365-72.

36. HEALTH AND DEMOGRAPHIC SURVEILLANCE SYSTEM-MATLAB Vol. 38, 2005, socio-economic census, Scientific Report No. 96 - February 2007. Available from: http://www.icddrb.org/what-we-do/publications/ doc_download/215-health-and-demographic-surveillance-system-matlab -volume-38-2005-socio-economic-census-sr96-2007 [Last accessed on 2012 Dec 21].

37. Gamble MV, Ahsan H, Liu X, Factor-Litvak P, Ilievski V, Slavkovich V, et al. Folate and cobalamin deficiencies and hyperhomocysteinemia in Bangladeshi. Am J Clin Nutr 2005;81:1372-7.

38. Pilsner JR, Liu X, Ahsan H, llievski V, Slavkovich V, Levy D, et al. Genomic methylation of peripheral blood leuko $\neg$ cyte DNA: Influences of arsenic and folate in Bangladeshi adults. Am J Clin Nutr 2007;86:1179-86.

39. Koebnick C, Heins UA, Hoffmann I, Dagnelie PC, Leitzmann C. Folate Status during Pregnancy in Women Is Improved by Long-term High Vegetable Intake Compared with the Average Western Diet. J Nutr 2001;131:733-9.

40. Pathak P, Kapil U, Yajnik CS, Kapoor SK, Dwivedi SN, Singh R. Iron, folate, and vitamin B12 stores among pregnant women in a rural area of Haryana State, India. Food Nutr Bull 2007;28:435-8.

41. Ahmed S, Rahman A, Hull S. Use of betel quid and cigarettes among Bangladeshi patients in an inner-city practice: Prevalence and knowledge of health effects. Br J Gen Pract 1997;47:431-4.

42. Khan SI, Ahmed AK, Yunus M, Rahman M, Hore SK, Vahter M, et al. Arsenic and cadmium in food-chain in Bangladesh-an exploratory study. J Health Popul Nutr 2010;28:578-84.

How to cite this article: Kader M. Association between betel nut consumption and folate deficiency among pregnant women in rural Bangladesh. Int J Med Public Health 2013;3:81-8.

Source of Support: Nil, Conflict of Interest: None declared. 